\title{
Introduction
}

This special issue on deaf-blindness, while four years in the making, offers some very timely and beneficial recommendations for family members, service providers and consumers interested in understanding the often misunderstood community of persons who are deaf-blind.

Prior to the National Conference on DeafBlindness held in Washington, DC, the Helen Keller National Center (HKNC) was asked to edit a Special Issue of the Journal of Vocational Rehabilitation that focused on the technological advances, recent medical, assessment and legislative issues that will have enormous impact on the deaf-blind population. Thus began this 4-year project to compile resource that could be used by professionals serving persons who are deaf-blind, employers, the medical community and deaf-blind consumers. This Special Issue draws upon the expertise and knowledge of seasoned professionals who have a proven track record in research and training on behalf of persons who are deafblind. In addition, this special issue provides the reader with the opportunity to meet a group of budding professionals who have already had noticeable effect on the quality and quantity of services available for persons who are deaf-blind.

In the early 1960 s this country experienced an epidemic that focused greater attention on the population of persons who are deaf-blind. It was believed that the Rubella Virus that plagued the country some 30 years ago had been contained. Recent findings suggest that there are still many cases of the virus since the mid 1960s. The children who were born during that epidemic are now adults participating in training centers, working at job sites and going to school. Much of the infor- mation derived from that group of youngsters is currently being analyzed and compiled to give educators and family members a better handle on the ramifications of the virus and the various late manifestations that have been puzzling professionals for decades. Answers to many questions involving this population will be provided in this Special Issue.

Rubella and Usher Syndrome have been known as a leading cause of deaf-blindness among persons who were deaf-blind. However, unlike Rubella, Usher Syndrome was said to be the leading cause of deaf-blindness for adults. While this remains a reality, recent studies suggest that there are a number of other syndromes and etiologies with which professionals will need to become familiar in order to keep pace with the ever changing faces of deaf-blindness.

Issues around mobility and gaining acceptance in inclusive settings remains a concern for the deaf-blind consumer. Many programs are looking to acquire a better understanding of the deaf-blind consumers who have been overlooked by the larger community for many years. Training for personal adjustment to an acquired disability such as Usher Syndrome is explored as well as functional and psychological assessments to meet the needs of this increasing population.

Legislatively, this is one of the most interesting and productive times for the disabled community. The new laws will have a far reaching impact on the manner in which education and training are provided to all persons who are disabled and specifically to those who are deaf-blind. DeafBlindness is classified as a severe disability. As a 
result persons who are deaf-blind are afforded a tremendous opportunity to access educational, vocational and personal adjustment training that may not always be available to other disability groups. Medically there have been numerous advances that have enhanced the lives of persons who are deaf-blind. One such surgical procedure known as the Cochlear Implant, while controversial, has provided new hope to some persons who are deaf-blind and wish to regain some use of their auditory modality.

Advances in technology had made it possible for some persons who are deaf-blind to access the world at a rate that is comparable to their non-disabled peers.

It is the hope of the editors that the readers will find the data compiled in this special issue to be both enlightening and of tremendous benefit as they begin to acquire knowledge for and about what is without question one of the fastest growing group of persons with disabilities in the country.

Cynthia L. Ingraham

East Central Represenative Helen Keller National Center

\section{About the Editors}

Cynthia L. Ingraham is the East Central Regional Representative for the Helen Keller National Center (HKNC) in Washington, DC. Ms. Ingraham, a certified teacher of the deaf, vision instructor for the blind, has worked in the disabil- ity field for the past 11 years. As regional representative for the HKNC, Ms. Ingraham trains, advocates and provides consultation to service providers and family members on behalf of consumers who are deaf-blind.

Dr. McCay Vernon is currently a consulting psychologist for the Springfield State Hospital in Springfield, MD. A former professor at Western Maryland College in Westminister, MD, Dr. Vernon's impressive career spans over 30 years. $\mathrm{He}$ has served as editor for the American Annals of the Deaf and has written over 250 articles and publications on the education and assessment of persons who are deaf and deaf-blind.

Barbara King has been employed by the West Virginia Department for Rehabilitative Services (WVDRS) for 21 years, and has been in the field of deafness for 16 years. For the past 5 years Ms. King has served as the State Coordinator for the Deaf and Deaf-Blind at WVDRS, where she is responsible for a statewide delivery system of services for individuals who are deaf or deaf-blind.

Marlene Jones Kinney is employed by the District of Columbia Department of Human Services, Rehabilitation Services Administration. A former rehabilitation counselor, for deaf and deaf-blind consumers, Ms. Kinney currently serves as the D.C. State Coordinator for Deaf and Deaf-Blind Services. In that capacity she supervises the staff of the Communication Impairment Section and assesses the need for, as well as develops, implements and monitors programs and policies for the provision of quality services to the city's deaf and deaf-blind communities. 